\title{
Hydrothermal Pretreatment of Date Palm (Phoenix dactylifera L.) Leaflets and Rachis to Enhance Enzymatic Digestibility and Bioethanol Potential
}

\author{
Chuanji Fang, ${ }^{1}$ Jens Ejbye Schmidt, ${ }^{1}$ Iwona Cybulska, ${ }^{1}$ Grzegorz P. Brudecki, ${ }^{1}$ \\ Christian Grundahl Frankær, ${ }^{2}$ and Mette Hedegaard Thomsen ${ }^{1}$ \\ ${ }^{1}$ Institute Center for Energy (iEnergy), Masdar Institute of Science and Technology, P.O. Box 54224, Abu Dhabi, UAE \\ ${ }^{2}$ Department of Chemistry, Technical University of Denmark, 2800 Kongens Lyngby, Denmark
}

Correspondence should be addressed to Mette Hedegaard Thomsen; mthomsen@masdar.ac.ae

Received 3 February 2015; Revised 18 March 2015; Accepted 28 March 2015

Academic Editor: Jungho Jae

Copyright (c) 2015 Chuanji Fang et al. This is an open access article distributed under the Creative Commons Attribution License, which permits unrestricted use, distribution, and reproduction in any medium, provided the original work is properly cited.

Date palm residues are one of the most promising lignocellulosic biomass for bioethanol production in the Middle East. In this study, leaflets and rachis were subjected to hydrothermal pretreatment to overcome the recalcitrance of the biomass for enzymatic conversion. Evident morphological, structural, and chemical changes were observed by scanning electron microscopy, X-ray diffraction, and infrared spectroscopy after pretreatment. High glucan ( $>90 \%$ for both leaflets and rachis) and xylan $(>75 \%$ for leaflets and $>79 \%$ for rachis) recovery were achieved. Under the optimal condition of hydrothermal pretreatment $\left(210^{\circ} \mathrm{C} / 10 \mathrm{~min}\right)$ highly digestible (glucan convertibility, $100 \%$ to leaflets, $78 \%$ to rachis) and fermentable (ethanol yield, $96 \%$ to leaflets, $80 \%$ to rachis) solid fractions were obtained. Fermentability test of the liquid fractions proved that no considerable inhibitors to Saccharomyces cerevisiae were produced in hydrothermal pretreatment. Given the high sugar recovery, enzymatic digestibility, and ethanol yield, production of bioethanol by hydrothermal pretreatment could be a promising way of valorization of date palm residues in this region.

\section{Introduction}

High worldwide demand for energy, unstable and uncertain petroleum sources, and concern over global climate change have led to a resurgence in the development of alternative energy that can displace fossil transportation fuel [1]. The idea of converting biomass-derived sugars to transportation biofuels was first proposed in the 1970s. Once again, the idea is being seriously contemplated as a possible substitute for petroleum-based liquid fuels. Economic and geopolitical factors (high oil prices, environmental concerns, and supply instability) have certainly played a role in reviving interest in renewable resources [2]. Evidence suggests that transportation fuels based on lignocellulosic biomass represent the most scalable alternative fuel source. Lignocellulosic biomass in the form of plant materials (e.g., grass, wood, and crop residues) offers the possibility of a renewable, geographically distributed, and greenhouse-gas-favorable source of sugars that can be converted to ethanol and other liquid fuels [3].
Geopolitical factors have strongly driven the research, as has commercialization of cellulosic biofuels in the past 7 years in North and South America, Europe, and China. The US Department of Energy (DOE) in 2008 established five research centers at a total cost of more than $\$ 300$ million. In addition, in 2009 DOE committed $\$ 480$ million to improve the energy efficiency of biofuels and biomass conversion plants. In the European Union (EU), the total contribution of biofuel projects (mostly second generation) under the Seventh Framework Program adds up to $€ 45$ million [4]. The first commercial-scale cellulosic ethanol refinery (owned by Beta Renewables, Italy) opened in Italy in 2013 [5]. DuPont Biofuel Solutions, a subsidiary of DuPont, is constructing a commercial-scale cellulosic ethanol facility built for an estimated \$276 million with a capacity of 25 MGY of ethanol near Nevada, IA. POET and DSM are jointly constructing a $20 \mathrm{MGY}$ cellulosic ethanol plant in Emmetsburg, IA [6]. In China, there were eight pilot and demonstration plants in 
operation by December 2009, with a total capacity of 280,500 tons bioethanol per year [7]. Due to the typical geography and climate of the Middle East, researches have been focusing on using marine (e.g., macroalgae) biomass [8], halophytes (e.g., Salicornia bigelovii) [9], and agricultural wastes (e.g., date palm fruit and sap) $[10,11]$ to produce bioethanol.

The date palm (Phoenix dactylifera L.) is a major fruit crop in most Middle Eastern countries. It has historically been connected to sustaining human life and traditional heritage of the people in the old world as a major agricultural crop. Middle Eastern countries possess 70\% of the 120 million world's date palms [12]. Generally, each date palm tree produces 10 to 30 dried leaves annually. An average naturally dried leaf (includes leaflets and rachis) has a mass of $2-3 \mathrm{~kg}$ [13]. Hence, each date palm is estimated to yield approximately $50 \mathrm{~kg}$ leaf residues per year. This means the annual yield of lignocellulosic feedstock from date palm leaf residues is over 4 million tons. Regardless of the abundant lignocellulosic biomass, to our knowledge, no study has been conducted on bioethanol production from lignocellulosic date palm residues.

Plant biomass has evolved complex structural and chemical mechanisms for resisting assault on its structural sugars from predators such as microbes, insects, and animals contributing to the recalcitrance of lignocellulosic feedstock to chemical or enzymatic conversion. A pretreatment step is usually conducted to reduce recalcitrance by depolymerizing and solubilizing hemicellulose. Removal of hemicellulose from the microfibrils is thought to expose the crystalline cellulose core, which can then be hydrolyzed by cellulolytic enzymes [1]. Hydrothermal pretreatment (also known as autohydrolysis or liquid hot water pretreatment) has attracted a great deal of attention because it can be considered as an eco-friendly green processing technology by using water and steam only. One of the most important benefits of using water instead of acid as pretreatment media is that it avoids corrosion problems, acid recycling, and the formation of neutralization sludge. Another advantage is that hydrothermal pretreatment tends to result in lower inhibiting hydrolyzates which can decrease yield in the subsequent fermentation process [14]. Petersen et al. [15] reported an optimum hydrothermal pretreatment condition of wheat straw to be $195^{\circ} \mathrm{C}$ for $6-12 \mathrm{~min}$, which yielded $70 \%$ hemicellulose recovery and $93-94 \%$ cellulose recovery in the fibers, and approximately $89 \%$ of the cellulose was converted into ethanol by commercial cellulase mixture. Kumar et al. [16] showed that almost $100 \%$ cellulose and $92 \%$ hemicellulose were recovered from hydrothermal pretreated switch grass, and more than $80 \%$ of glucan digestibility was achieved at $190^{\circ} \mathrm{C}$ for $20 \mathrm{~min}$. In the study of Romaní et al. [17] up to $94 \%$ of polysaccharides were recovered in the hydrolysis media as mono- or oligosaccharides when using Eucalyptus globulus wood pretreated at $220^{\circ} \mathrm{C}$.

Despite the wide interest in biomass for energy production scaling up experimental projects to commercial operations is not easy [18]. Estimation of energy (e.g., bioethanol) production potential is a necessary starting point to reveal the specific dynamics and interrelationships between environmental and socioeconomic systems [19].
Wild-type S. cerevisiae strains readily ferment C6 sugars including glucose, mannose, fructose, and galactose as well as the disaccharides sucrose and maltose [20]. On the other hand, other of the most abundant sugar monomers from biomass D-xylose and L-arabinose (C5 sugars) require either extensive metabolic engineering of $S$. cerevisiae [20] or other fermentative organisms such as Kluyveromyces marxianus [21], Zymomonas mobilis [22], and Pichia stipitis [21].

The primary focus of this research is to evaluate lignocellulosic biomass of date palm (leaflets and rachis) as potential bioethanol feedstock. Hydrothermal treatment was chosen as a pretreatment method of overcoming biomass recalcitrance prior to enzymatic hydrolysis and fermentation in order to facilitate high yield in both processes. Morphological and chemical changes by pretreatment were observed by scanning electron microscopy (SEM) and attenuated total reflectionFourier transform infrared spectroscopy (ATR-FTIR). X-ray diffraction (XRD) was used to compare the crystallinity of date palm leaflets and rachis before and after hydrothermal pretreatment.

\section{Materials and Methods}

2.1. Materials and Preparation. Leaves were collected from date palm trees in Abu Dhabi in 2013. Leaflets and rachis were separated from leaves. They were dried and stored before use. The dried material was milled using a knife mill (IKA, $10 \mathrm{MF}$ Basic) to pass through a $1 \mathrm{~mm}$ screen.

2.2. Biomass Chemical Composition Analysis. Sequential Soxhlet extractions with water and ethanol were performed based on National Renewable Energy Laboratory (NREL) protocol [23]. Structural carbohydrates and lignin of extractives-free date palm leaflets and rachis before and after hydrothermal pretreatment were subjected to two-step acid hydrolysis according to the analytical procedure of NREL [24]. The hydrolyzates were analyzed for sugars using High Performance Liquid Chromatography (Agilent 1260 Infinity Bio-Inert Binary LC). The Hi Plex-H column (Agilent) and refractive index detector (RID) were used to determine the concentrations of glucose, xylose, and arabinose at $65^{\circ} \mathrm{C}$ using $0.005 \mathrm{M} \mathrm{H}_{2} \mathrm{SO}_{4}$ as the mobile phase (eluent) with a flow rate of $0.6 \mathrm{~mL} / \mathrm{min}$.

2.3. Hydrothermal Pretreatment. Hydrothermal pretreatment experiments were performed at $10 \% \mathrm{w} / \mathrm{w}$ dry matter loading, at four temperature levels $\left(180,190,200\right.$, and $\left.210^{\circ} \mathrm{C}\right)$. Processing time was maintained at $10 \mathrm{~min}$. Combined severity factors corresponding to each condition were calculated [25]

$$
\begin{aligned}
& \text { CS (combined severity) } \\
& \quad=\log \left(R_{o}\right)-\mathrm{pH}=\log \left(t \exp \left(\frac{T-100}{14.75}\right)\right)-\mathrm{pH},
\end{aligned}
$$

where $T$ is temperature, ${ }^{\circ} \mathrm{C}$; $t$ is time, $\min ; R_{o}$ is severity factor.

The pretreatment was conducted in a Parr reactor (Parr Instrument Company, Moline, Illinois) with working volume 
of 1 liter. For all experiment, it took less than 15 minutes to reach the targeted temperature, and the relaxation time was short $(<10 \mathrm{~min})$. After the treatment, the reactor was cooled to $40^{\circ} \mathrm{C}$ and the pretreated material was separated by filtration into solid (fibers) and liquid fraction (filtrate). Both fractions were kept at $4^{\circ} \mathrm{C}$ until analysis and further processing. Further processing included the following: composition analysis of the fiber and liquid fractions, enzymatic hydrolysis of fibers, convertibility of the fibers in SSF with S. cerevisiae, and fermentability by $S$. cerevisiae of the liquid fraction. Mass balance of all the crucial components (glucan and xylan) was performed using (2)-(4). Content of these components in the solid fractions was measured using two-step acid hydrolysis [24], while their amount in the liquid fractions (filtrates) was measured using dilute-acid hydrolysis described later in this section:

$$
\text { Dry Mass in }(\mathrm{g})=\frac{\mathrm{TS}_{\text {raw }} * W_{\text {initial biomass }} * C_{\text {raw }}}{100 * 100},
$$

where $W_{\text {initial biomass }}$ is weight of the initial biomass fed into the pretreatment [g]; $\mathrm{TS}_{\text {raw }}$ are total solids in the raw biomass [\%]; $C_{\text {raw }}$ is content of the specific component in the raw biomass measured by strong acid hydrolysis [g/100 g TS]. Thus,

$$
\operatorname{Dry} \text { Mass out }(\mathrm{g})=\frac{\mathrm{TS}_{\text {pretreated }} * W_{\text {fibers }} * C_{\text {fibers }}}{100 * 100},
$$

where $W_{\text {fibers }}$ is weight of the biomass in fiber fraction after the pretreatment $[\mathrm{g}]$; $\mathrm{TS}_{\text {pretreated }}$ are total solids of the pretreated biomass [\%]; $C_{\text {fibers }}$ is content of the specific component in the fiber fraction after the pretreatment measured by strong acid hydrolysis [g/100 g TS]. Hence,

Fiber fraction recovery $\%$

$$
=\frac{\text { Dry mass out }(\mathrm{g})}{\text { Dry mass in }(\mathrm{g})} * 100 \% \text {, }
$$

Liquid fraction recovery $\%$

$$
=\frac{\text { Amount in the filtrate }(\mathrm{g})}{\text { Dry mass in }(\mathrm{g})} * 100 \% \text {. }
$$

\subsection{Fiber Fraction Analysis and Further Processing}

2.4.1. Fiber Composition Analysis. The pretreated fibers were subjected to two-step acid hydrolysis [24] to determine sugar recovery. The process was carried out following the same protocol as in the case of the extractives-free raw leaflets and rachis described above in Section 2.2.

2.4.2. Enzymatic Hydrolysis. Enzymatic convertibility assay based on commercial Cellic CTec2 (117 FPU/mL, protein content $194 \mathrm{mg}$ protein/mL) and Cellic HTec2 enzymes (Novozymes A/S, Denmark) was used to determine the efficiency of the pretreatment. Protein concentration of enzymes was determined as described by Bradford [26]. The hydrolysis was performed according to National Renewable Energy Laboratory protocol [27] using $100 \mathrm{~g} / \mathrm{L}$ dry biomass loading and
15 FPU cellulase/g dry matter of biomass (with cellulase-tohemicellulase ratio of $1: 9$ ). The process was performed in the presence of $50 \mathrm{mM}$ citrate buffer $(\mathrm{pH} 5)$ at $50^{\circ} \mathrm{C}$ and samples were shaken at $150 \mathrm{rpm}$ for $72 \mathrm{~h}$. Glucose released during the enzymatic hydrolysis was quantified using HPLC at the same operating conditions as applied in the acid hydrolysis samples (described above). Enzymatic convertibilities of cellulose to glucose and xylan to xylose were calculated using

$$
\text { Convertibility }(\%)=\frac{C_{\text {glucose/xylose }}}{L *\left(C_{\text {fibers }} / 100 \text { g TS }\right)} * 100 \% \text {, }
$$

where $C_{\text {glucose/xylose }}$ is concentration of glucose/xylose measured in the enzymatic hydrolyzate $[\mathrm{g} / \mathrm{L}] ; L$ is fibers loading $[\mathrm{g} / \mathrm{L}] ; C_{\text {fibers }}$ is content of the specific component (glucose or xylose) in the fiber fraction after the pretreatment $[\mathrm{g} / 100 \mathrm{~g}$ TS].

Based on the glucose and xylose yield by enzymatic hydrolysis, bioethanol potential was calculated using

$$
\begin{aligned}
& \text { Bioethnaol potential }\left(\frac{\mathrm{kg}}{t \text { dry biomass }}\right) \\
& =1000 * C_{\mathrm{glu} / \mathrm{xyl}} * \frac{1}{100} * R_{\mathrm{glu} / \mathrm{xyl}} \\
& \quad * f_{\text {carbohydrate-to-monosugar }} * Y_{\mathrm{glu} / \mathrm{xyl}} * 0.511,
\end{aligned}
$$

where $C_{\text {glu/xyl }}$ is glucan/xylan content in raw biomass $[\mathrm{g} / 100 \mathrm{~g}$ TS]; $R_{\text {glu/xyl }}$ is glucose/xylose recovery; $f_{\text {carbohydrate-to-monosugar }}$ is glucan-to-glucose factor (1.11), xylan-to-xylose factor (1.14); $Y_{\text {glu/xyl }}$ is glucose/xylose conversion by enzymatic hydrolysis; 0.511 is glucose/xylose-to-ethanol factor [19].

2.4.3. Simultaneous Saccharification and Fermentation (SSF). The fermentation mixture was prepared in $250 \mathrm{~mL}$ flasks using $100 \mathrm{~mL}$ total volume. The flasks were secured with yeast locks to ensure anaerobic conditions while enabling carbon dioxide release. The mixture was composed of enzymes (types and doses the same as for enzymatic hydrolysis), $\mathrm{pH}$ buffer (to maintain the $\mathrm{pH}$ at 5.0), and 10\% DM (dry mass) biomass loading. The mixture was prehydrolyzed for 24 hours at $50^{\circ} \mathrm{C}$ and $150 \mathrm{rpm}$ in a shaking bed incubator. After the prehydrolysis the solution was cooled to $32^{\circ} \mathrm{C}$ and $0.2 \mathrm{~g}$ of dry Baker's yeast ( $S$. cerevisiae) was added along with urea as nutrients source $(0.2 \mathrm{~mL}$ of a $24 \%$ urea solution). The process was performed at $32^{\circ} \mathrm{C}$ with constant shaking $(90 \mathrm{rpm})$ for 72 hours. Weight measurements of the flasks were recorded throughout the duration of the process. The weight loss (representing release of carbon dioxide) was translated to ethanol yield using (7). Final ethanol concentration was determined by the HPLC analysis:

$$
W_{\text {ethanol }}=\frac{1 \mathrm{~mol} \mathrm{EtOH}}{1 \mathrm{~mol} \mathrm{CO}_{2}} * \frac{M_{\text {ethanol }}}{M_{\mathrm{CO}_{2}}} * W_{\mathrm{CO}_{2}},
$$

where $W_{\text {ethanol }}$ is weight of ethanol $(\mathrm{EtOH})$ produced [g]; $M_{\text {ethanol }}$ is molar mass of ethanol [ $\left.46 \mathrm{~g} / \mathrm{mol}\right] ; M_{\mathrm{CO}_{2}}$ is molar mass of $\mathrm{CO}_{2}[44 \mathrm{~g} / \mathrm{mol}] ; W_{\mathrm{CO}_{2}}$ is weight of $\mathrm{CO}_{2}$ produced $=$ weight loss of the fermentation flask [g]. 
Theoretical ethanol yield was determined based on the glucan content in the raw material following (8). Ethanol yield (\%) was calculated as a percent ratio of the actual ethanol amount produced to the theoretical ethanol yield (9):

$$
\mathrm{TY}_{\text {ethanol }}=0.511 * C_{\text {glucan }} * L * 1.11
$$

where $\mathrm{TY}_{\text {ethanol }}$ is theoretical ethanol yield $[\mathrm{g}]$; $C_{\text {glucan }}$ is glucan content in fibers; $L$ is fibers loading $[\mathrm{g} / \mathrm{L}]$; 0.511 is glucose-to-ethanol factor; 1.11 is glucan-to-glucose factor. Hence,

$$
Y_{\text {ethanol }}=\frac{\text { Ethanol produced }(\mathrm{g})}{\mathrm{TY}_{\text {ethanol }}(\mathrm{g})} * 100 \%
$$

\subsection{Liquid Fractions (Filtrates) Analysis}

2.5.1. Analysis of Free Sugars and Pretreatment By-Products. Liquid fractions were analyzed for the released (free) monomeric sugars including glucose, xylose, and arabinose and for the pretreatment by-products (mostly sugar degradation products) including acetic acid, furfural, and HMF. The analysis was performed using HPLC with the same operating conditions as described above.

2.5.2. Dilute-Acid Hydrolysis. To determine the quantity of the oligomers of xylose, arabinose, and glucose in the pretreated liquid fraction (filtrate) dilute-acid hydrolysis was carried out with $8 \%$ w/w $\mathrm{H}_{2} \mathrm{SO}_{4}$ solution according to Cybulska et al. [9]. The ratio of the sample to acid was $1: 1$, producing a final acid concentration of $4 \% \mathrm{w} / \mathrm{w}$. The solution was autoclaved at $121^{\circ} \mathrm{C}$ for $10 \mathrm{~min}$. Sugar recovery measurement was performed and the recovery factor was included in the calculations to account for sugar losses to degradation. The hydrolyzates were analyzed using the HPLC system to measure the concentrations of the simple sugars released. The results were then used in the mass balance recovery calculations for the sugars, as described above.

2.5.3. Fermentability Study. Fermentability study was done according to Cybulska et al. [9]. The liquid fractions obtained from the pretreatment process were fermented in order to test the possibility of using the filtrates as fermentation medium. Since the liquid fraction contains fewer hexoses (as compared to solid fractions) and more inhibitors, glucose $(35 \mathrm{~g} / \mathrm{L})$ was added to the fermentation solution. Flasks containing hydrolysates, glucose, and $2 \mathrm{~g} / \mathrm{L}$ of $S$. cerevisiae were incubated at $32^{\circ} \mathrm{C}$ and $100 \mathrm{rpm}$. Weight loss measurements were taken once a day for 72 hours, and the weight loss was converted to ethanol yield using (9).

2.6. Scanning Electron Microscopy (SEM). A Quanta 250 (FEI, Oregon, USA) scanning electron microscopy operated at $2 \mathrm{keV}$ was used to image leaflets and rachis before and after pretreatment. Samples were coated with gold using a vacuum sputter-coater to improve the conductivity of the samples and thus the quality of the SEM images.
2.7. Attenuated Total Reflection-Fourier Transform Infrared Spectroscopy (ATR-FTIR). Attenuated total reflectionFourier transform infrared spectroscopy (ATR-FTIR) was conducted using a Bruker Optics Vertex system (Bruker, Massachusetts, USA) with built-in diamond-germanium ATR single reflection crystal. Leaflets and rachis before and after pretreatment were pressed uniformly against the diamond surface using a spring loaded anvil. Sample spectra were obtained using an average of 64 scans over the range of 500 and $4,000 \mathrm{~cm}^{-1}$ with a spectral resolution of $4 \mathrm{~cm}^{-1}$.

2.8. X-Ray Diffraction (XRD). Dewaxing [28] was deployed in leaflets (with and without pretreatment) to avoid the crystallographic interference by wax. Rachis (with and without pretreatment) and dewaxed leaflets were analyzed by Empyrean X-ray diffractometer (PANalytical, Eindhoven, Netherlands) equipped with a PIXcel3D detector and operated at $45 \mathrm{kV}$ and $40 \mathrm{kA}$ using $\mathrm{Cu} \operatorname{K} \alpha$ radiation $(\lambda=1.5418 \AA)$. Powder diffraction data were collected in reflection geometry in the $2 \theta$ range of 10 to $40^{\circ}$ with a step size of $0.008^{\circ}$ and a counting time of $10 \mathrm{~s}$ per step.

The Rietveld method was adopted to estimate the percent crystallinity in the biomass samples as this method takes into account the overlapping and widely broadened diffraction peaks of cellulose [29]. Refinements were performed as described by Thygesen et al. [29] using the crystal structure of cellulose $\mathrm{I} \beta$ as input. The peak shapes were modeled by the Voigt function, and a total of 15 parameters were refined to find the best fit for all samples. The best parameter set included refinement of one scale factor, 10 Chebyshev background parameters, one parameter accounting for the sample transparency effect, one Voigt peak profile parameter, the unit cell parameter $b$, and one preferred orientation parameter along (130). Other unit cell parameters were fixed to those reported by de Figueiredo and Ferreira [30].

\section{Results and Discussions}

3.1. Composition Analysis and Sugar Recovery. The main chemical components (glucan, xylan, arabinan, and lignin) of leaflets and rachis before and after pretreatment are shown in Figure 1(a). Glucan and xylan content was $20.62 \%$ and $10.53 \%$ (based on dry matter) in leaflets, while it was $38.34 \%$ and $20.07 \%$ in rachis. Lignin content in leaflets and rachis was $30.54 \%$ and 24.61 , respectively. The remaining components were mainly extractives and ashes. Solids recovery for all pretreated biomass was more than 97\% (data not shown). Both glucan and lignin content increased (percent basis) significantly after pretreatment. The highest glucan and lignin content was $31.63 \%$ and $64.95 \%$ in pretreated leaflets at $210^{\circ} \mathrm{C}$ and was $60.12 \%$ for glucan at $200^{\circ} \mathrm{C}$ and was $45.95 \%$ for lignin at $210^{\circ} \mathrm{C}$ in pretreated rachis. Xylan contents in pretreated leaflets and rachis both decreased, with the lowest value observed at $210^{\circ} \mathrm{C}$ (3.07\% for leaflets and $4.22 \%$ for rachis).

High sugars recoveries were obtained by hydrothermal pretreatment of leaflets and rachis (Figures 1(b) and 1(c)). Glucan recoveries of both pretreated leaflets and rachis were above $90 \%$. More than $75 \%$ and $79 \%$ xylan was recovered 


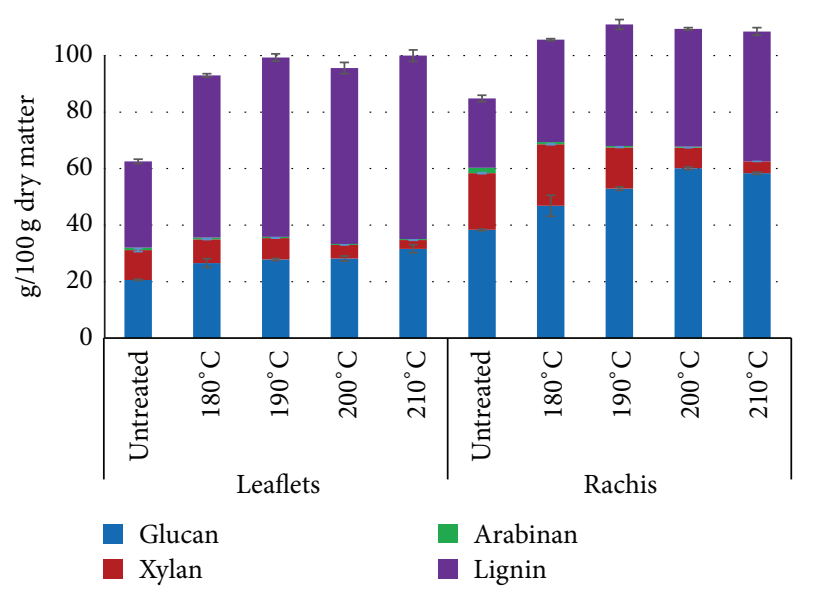

(a)

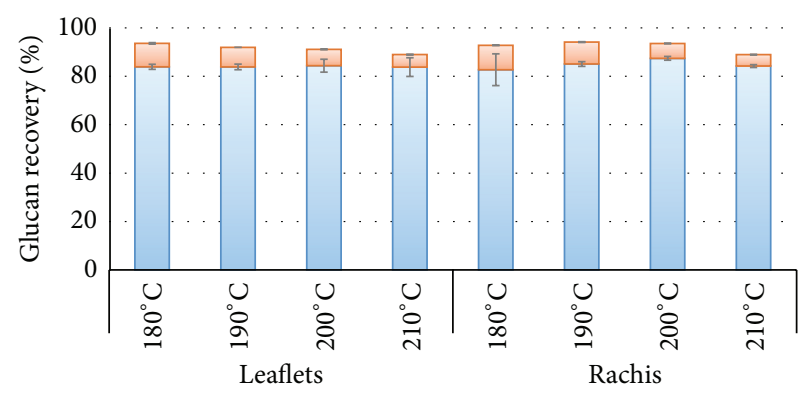

$\square$ Glucan recovery from solids

$\square$ Glucan recovery from liquids

(b)

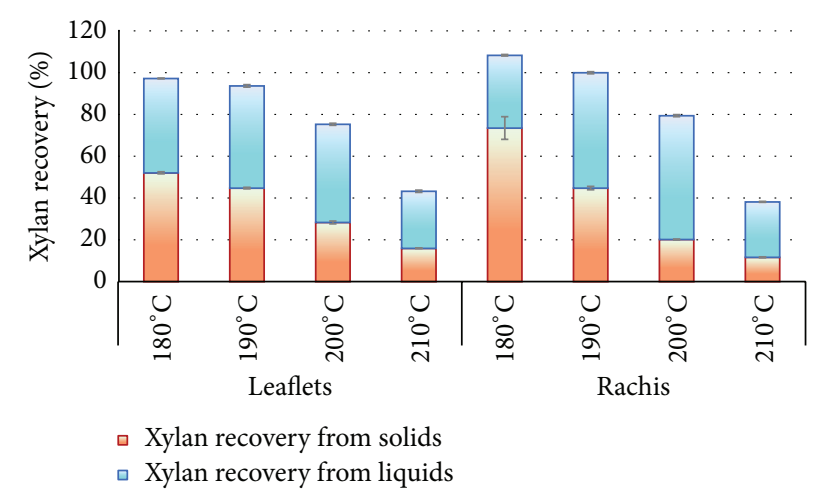

(c)

Figure 1: Main chemical components and sugar recovery of leaflets and rachis of before and after hydrothermal pretreatment. (a) Main chemical components (glucan, xylan, arabinan, and lignin) analysis. (b) Glucan recovery from solids and liquids of pretreated leaflets and rachis. (c) Xylan recovery from solids and liquids of pretreated leaflets and rachis.

from pretreated leaflets and rachis, respectively, except those pretreated at $210^{\circ} \mathrm{C}$. There was a dramatic drop of xylan recovery (less than 50\%) for either biomass when the temperature was higher than $200^{\circ} \mathrm{C}$. In solids, more than $80 \%$ of glucan was recovered in pretreated leaflets and rachis. While only less than $10 \%$ glucan was recovered from liquids. By contrast, maximum xylan recovery was $52 \%$ and $74 \%$ in solids of pretreated leaflets and rachis. Relatively low xylan recoveries in solid fractions were results of leaching of xylan to liquid fractions (27\%-49\% for leaflets and 27\%-74\% for rachis).

Composition analysis (Figure 1(a)) shows that carbohydrate contents (glucan and xylan) of rachis are comparably high with conventional lignocellulosic biomass around the world like corn stover (30\%-38\% and 20\%-25\%), wheat straw (34\%-40\% and $21 \%-26 \%)$, and sugarcane bagasse $(32 \%-43 \%$ and $22 \%-25 \%$ ) [31]. Moreover, rachis has slightly lower lignin content than other woody biomass like eucalyptus (29-32\%) and pine (28\%) [32]. Given the high carbohydrates and low lignin content, date palm rachis seems to be a potential source of woody biomass for biorefinery. Conversely, leaflets have significantly lower carbohydrates content and higher lignin content than conventional lignocellulosic biomass, making date palm leaflets a potential biomass candidate for lignin production. The obvious increases of glucan and lignin content in the pretreated biomass are mainly due to the removal of xylan whose degradation is more sensitive to temperature. The results in Figures 1(b) and 1(c) show that hydrothermal pretreatment is capable of achieving high glucan (higher than 90\%) and xylan (higher than 75\%) recovery at moderate pretreatment conditions $\left(180-200^{\circ} \mathrm{C}\right)$ without adding any chemicals, which is agreeing with the work done on other conventional lignocellulosic biomass including wheat straw, switchgrass, and Eucalyptus globulus wood [1416]. Combined severity factor is often used to describe the removal of lignin and solubilization of xylan. There is a good correlation between the combined severity factor and xylan recovery of pretreated leaflets $\left(R^{2}=0.93\right)$ and rachis $\left(R^{2}=0.89\right)$, showing the potential of using combined severity factor as an index of xylan recovery in pretreatment process optimization. Similar trend was observed in other studies on hydrothermal pretreatment of S. bigelovii straw [9] and dilute sulfuric acid pretreatment of corn stover [33].

3.2. Effect of Hydrothermal Pretreatment on Morphological Changes. The surface morphologies of raw (before pretreatment) leaflets and rachis and pretreated ones are shown 


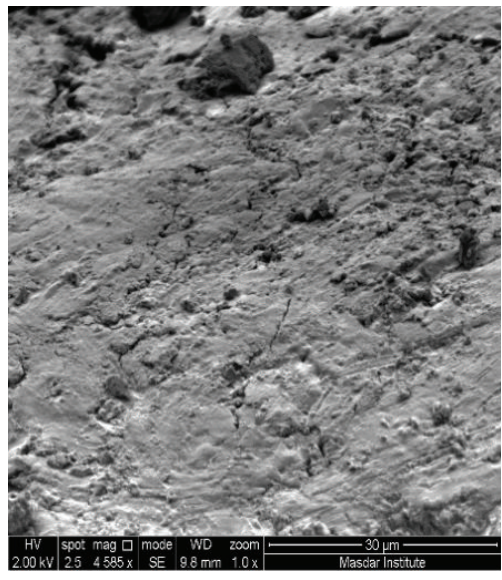

(a)

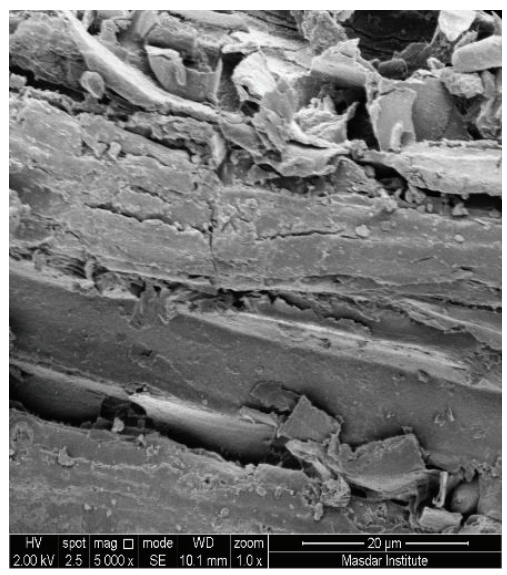

(d)

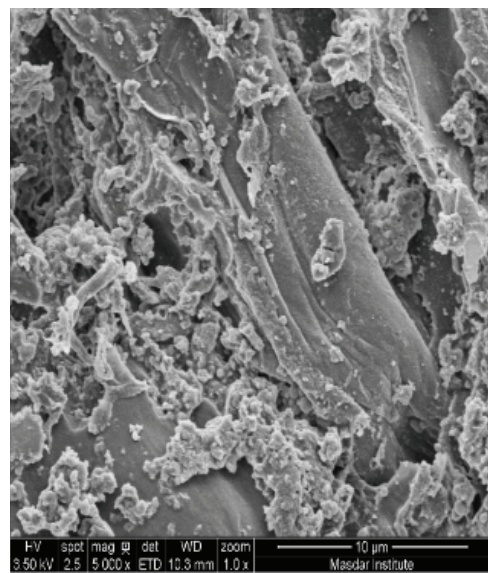

(b)

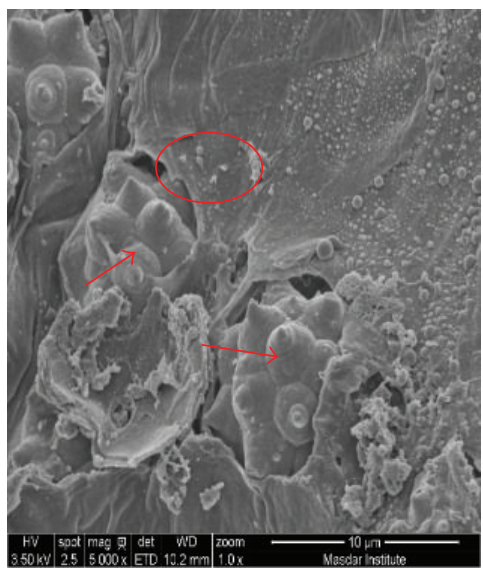

(e)

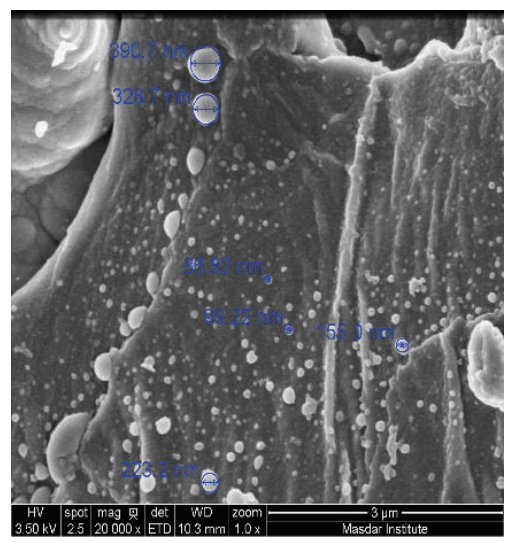

(g)

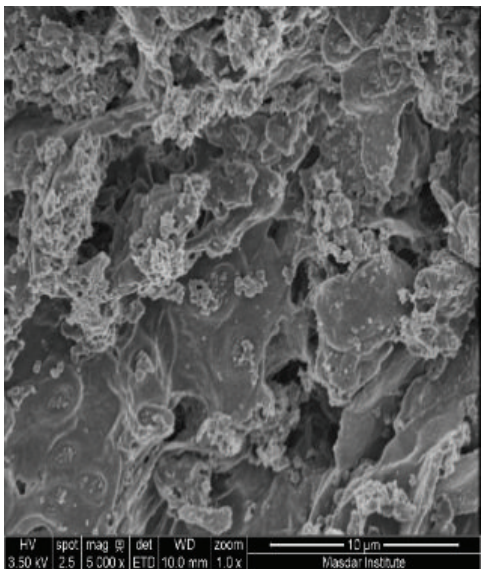

(c)

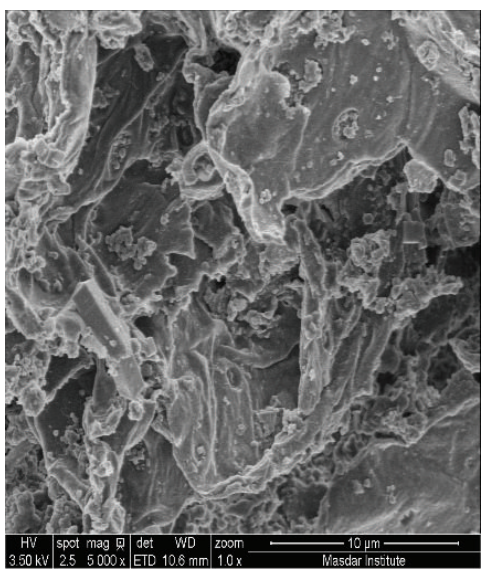

(f)

FIGURE 2: Scanning electron micrographs of untreated and pretreated date palm leaflets and rachis. (a) Raw leaflets. (b) and (c) Leaflets treated at $180^{\circ} \mathrm{C}$ and $210^{\circ} \mathrm{C}$, respectively. (d) Raw rachis. (e) and (f) Rachis treated at $180^{\circ} \mathrm{C}$ and $210^{\circ} \mathrm{C}$, respectively. (g) Magnified red circle area in (e). Red arrows represent crystallites in (e).

in Figures 2(a)-2(f). Figure 2(g) is the magnified image of the area labelled in red circle on Figure 2(e). Surface of rachis (Figure 2(d)) was more irregular than that of leaflets (Figure 2(a)). A few bundles of fibers were observed on the surface of rachis. In addition, there was evident morphological contrast of leaflets and rachis before and after pretreatment according to Figures 2(a)-2(f). Structure of biomass after pretreatment was greatly changed, forming a variety of 


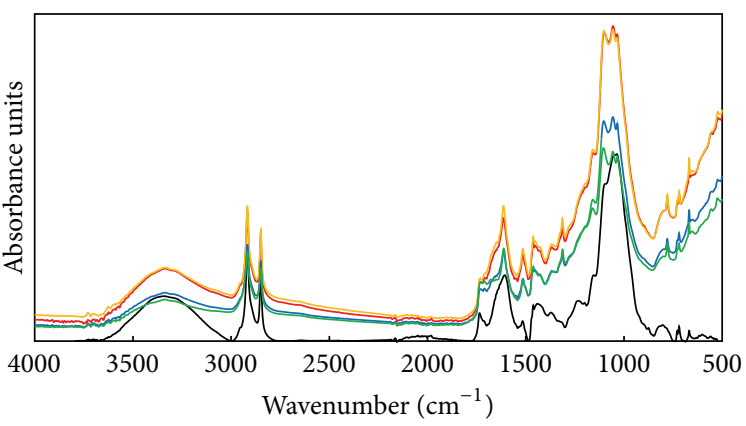

(a)

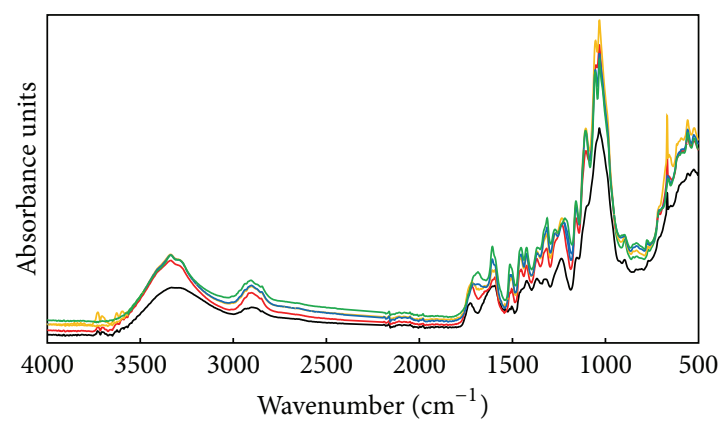

(b)

FIGURE 3: Attenuated total reflection-Fourier transform infrared spectroscopy (ATR-FTIR) of date palm leaflets and rachis. (a) FTIR spectra of the date palm leaflets in the range of 3,500 to $500 \mathrm{~cm}^{-1}$. The black line represents the leaflets. The red line, yellow line, blue line, and green line represent the pretreated leaflets at $180^{\circ} \mathrm{C}, 190^{\circ} \mathrm{C}, 200^{\circ} \mathrm{C}$, and $210^{\circ} \mathrm{C}$, respectively. (b) FTIR spectra of the date palm rachis in the range of 3,500 to $500 \mathrm{~cm}^{-1}$. The black line represents the rachis. The red line, yellow line, blue line, and green line represent the pretreated leaflets at $180^{\circ} \mathrm{C}, 190^{\circ} \mathrm{C}, 200^{\circ} \mathrm{C}$, and $210^{\circ} \mathrm{C}$, respectively.

smaller fragments. The changes caused by pretreatment at $210^{\circ} \mathrm{C}$ were more significant than those by treatment at $180^{\circ} \mathrm{C}$ for both leaflets and rachis. Spherical droplets with smooth surface texture (less than $1 \mu \mathrm{m}$ in diameter) scattering on the surface were noticed after pretreatment as shown in Figures $2(\mathrm{e})$ and $2(\mathrm{~g})$. Figure $2(\mathrm{e})$ (rachis pretreated at $180^{\circ} \mathrm{C}$ ) showed some crystallites half buried, which were not observed in Figure 2(f) (rachis pretreated at $210^{\circ} \mathrm{C}$ ).

Hydrothermal pretreatment caused significant morphological changes to both leaflets and rachis, showing the effectiveness of the pretreatment. Generally, higher pretreatment temperature caused more destruction of cell wall structure of both leaflets and rachis. Consequently, the destruction of cell wall increases the surface areas that are accessible to cellulolytic enzymes, which enhances cellulose enzymatic convertibility of lignocellulosic biomass. Donohoe et al. [34] characterized the resulting surface features of pretreated corn stover by several techniques, such as FTIR, NMR (nuclear magnetic resonance) analysis, antibody labeling, and cytochemical staining. It was hypothesized that thermochemical pretreatments reaching temperatures above the range of lignin phase transition caused lignin to coalesce into larger molten bodies that migrate within and out of the cell wall and can redeposit on the surface of plant cell walls. In our observations, the droplets exhibited similar physical features described in [34-36] based on their shape (spherical), size (up to $1 \mu \mathrm{m}$ ), and surface texture (smooth exterior). Another hypothesis for the spherical droplets is that they are pseudolignin derived from carbohydrate like xylan during severe hydrothermal pretreatment $[37,38]$. Lignin and lignin-like material (pseudolignin) was hypothesized to be responsible for the spherical droplets formation as visualized by SEM in our study. It was reported in other studies that the spherical droplets formation is possibly responsible for lower enzyme efficiency during enzymatic hydrolysis of pretreated materials, which was suspected to be caused by reduced accessibility of enzymes to substrates $[36,39]$. The crystallites found in Figure 2(e) (labeled by red arrows) are probably the minerals exuding from fibers and vessels. The presence of these crystal minerals confirms the conductive function of the fibers and vessels [40].

\subsection{Effect of Hydrothermal Pretreatment on Chemical and} Structural Changes. Tracking the chemical and structure changes of cellulose, hemicellulose, and lignin by FTIR facilitates mechanical study of the effects of pretreatment on the enzymatic digestibility of biomass. Table 1 describes the FTIR absorbance bands used to monitor the chemical and structure changes of lignocellulosic biomass. Figures 3(a) and 3(b) show the spectroscopy of date palm leaflets and rachis in the range of 3,500 to $500 \mathrm{~cm}^{-1}$.

The small band at $900 \mathrm{~cm}^{-1}$ representing amorphous cellulose was observed in rachis while it was hardly found in leaflets, showing one of the differences of crystallinity between leaflets and rachis. Moreover, rachis samples showed increase of amorphous cellulose peak intensity when increasing the pretreatment temperature from $180^{\circ} \mathrm{C}$ to $210^{\circ} \mathrm{C}$. It indicated that more amorphous cellulose was achieved by hydrothermal pretreatment with increased pretreatment severity. Another band around $1,098 \mathrm{~cm}^{-1}$ responsible for crystalline cellulose was observed in both leaflets and rachis. Stronger peaks at around $1,098 \mathrm{~cm}^{-1}$ were generated after pretreatment of both leaflets and rachis, suggesting an increasing proportion of crystalline cellulose in pretreated biomass due to the removal of amorphous cellulose compared with raw biomass. For leaflets, the wide band at around $1,035 \mathrm{~cm}^{-1}$ diverged into two small peaks at $1,035 \mathrm{~cm}^{-1}$ and $1,045 \mathrm{~cm}^{-1}$ after pretreatment. Similar change of band at around $1,035 \mathrm{~cm}^{-1}$ was observed between raw rachis and pretreated ones. These bands can be assigned to different bonds vibration coming from lignin, cellulose, and hemicellulose (Table 1). The region around $1,247 \mathrm{~cm}^{-1}$ was characterized to represent hemicellulose and lignin disappears after pretreatment of leaflets. Pretreated leaflets and rachis exhibited stronger peaks than untreated ones at three peaks $(1,465,1510$, and $1,595 \mathrm{~cm}^{-1}$ ) that are responsible for lignin. 
TABLE 1: FTIR absorbance bands in biomass study (adapted from [41, 54-56]).

\begin{tabular}{lcc}
\hline Wavenumber $\left(\mathrm{cm}^{-1}\right)$ & & Polymer \\
\hline 900 & Glycosidic bond & Cellulose (amorphous) [54] \\
1035 & C-O, C=C, and C-C-O stretching & Cellulose, hemicellulose, and lignin [55] \\
1045 & C-C, C-OH, C-H ring, and side group vibrations & Lignin [56] \\
1098 & Glycosidic bond & Cellulose (crystalline) [54] \\
1160 & C-O-C asymmetrical stretching & Cellulose, hemicellulose [55] \\
1247 & C-O stretching & Hemicellulose, lignin [41] \\
1465 & C-H deformation & Lignin [54] \\
1510 & Aromatic ring vibration & Lignin [54] \\
1595 & Aromatic ring vibration + C=O stretching & Lignin [54] \\
2840,2937 & C-H stretching & Lignin [54] \\
3421 & O-H stretching & Lignin [54]
\end{tabular}

TABLE 2: Crystallinity analysis of leaflets and rachis before and after hydrothermal pretreatment according to Rietveld method.

\begin{tabular}{|c|c|c|c|c|c|}
\hline & \multicolumn{5}{|c|}{ Samples } \\
\hline & Leaflets & Leaflets_180 & Leaflets_190 & Leaflets_200 & Leaflets_210 \\
\hline Crystallinity (\%) & 29.3 & 43.2 & 42.1 & 38.4 & 39.1 \\
\hline \multirow[t]{2}{*}{$R_{\mathrm{wp}}(\%)^{\mathrm{a}}$} & 3.80 & 3.57 & 3.56 & 3.73 & 3.78 \\
\hline & Rachis & Rachis_180 & Rachis_190 & Rachis_200 & Rachis_210 \\
\hline Crystallinity (\%) & 39.5 & 47.3 & 46.2 & 45.4 & 40.4 \\
\hline$R_{\mathrm{wp}}(\%)^{\mathrm{a}}$ & 3.51 & 3.69 & 3.55 & 3.68 & 3.93 \\
\hline
\end{tabular}

${ }^{\mathrm{a}}$ The weighted profile residual is given as $R_{\mathrm{wp}}=\left[\Sigma_{i} w_{i}\left(I_{\mathrm{obsi}}-I_{\mathrm{calc} i}\right)^{2} / \Sigma_{i} w_{i}\left(I_{\mathrm{obsi}}\right)^{2}\right]^{1 / 2}$, where $I_{\mathrm{obs}}$ and $I_{\text {calc }}$ are the observed and calculated intensity, respectively, and $w$ is the weighting function, $1 / I_{\mathrm{obs}}$.

The pretreatment increases the crystallinity of cellulose for both leaflets and rachis. Only for rachis the decrease of crystalline cellulose was observed when raising temperature from $180^{\circ} \mathrm{C}$ to $210^{\circ} \mathrm{C}$. It is consistent with the crystallinity profiles shown in Table 2 . The signal in region between 1,200 and $1,000 \mathrm{~cm}^{-1}$ is a large contribution of hemicellulose and cellulose, which exhibits a maximum value around $1,035 \mathrm{~cm}^{-1}$ and $1,160 \mathrm{~cm}^{-1}$ [41]. The divergence of band at around $1,035 \mathrm{~cm}^{-1}$ into two small peaks at $1,035 \mathrm{~cm}^{-1}$ and $1,045 \mathrm{~cm}^{-1}$ after pretreatment indicates removal of hemicellulose and accordingly increase of lignin. Regarding the bands at $1,160 \mathrm{~cm}^{-1}$, pretreated rachis shows stronger peaks than the untreated, while there are no obvious changes of peaks before and after pretreatment of leaflets, suggesting a more significant compositional change of cellulose and hemicellulose in pretreated rachis. The disappearance of band at around $1,247 \mathrm{~cm}^{-1}$ for pretreated leaflets is another evidence of the removal of hemicellulose by hydrothermal pretreatment. Considering changes to lignin fraction after pretreatment, peaks at $1,465,1510$, and $1,595 \mathrm{~cm}^{-1}$ are stronger than those before pretreatment, indicating the increase of lignin content after pretreatment due to the removal of hemicellulose.

\subsection{Effect of Hydrothermal Pretreatment on Crystallinity} Changes. Crystallinity in biomass is an important characteristic that has been shown to affect cellulose enzymatic digestibility [42]. Table 2 shows the crystallinity of leaflets and rachis before and after pretreatment based on Rietveld method. The powder patterns and Rietveld fits are included as Supplementary Material (Figure S.1 available online at http://dx.doi.org/10.1155/2015/216454). The set of refinement parameters used resulted in good fits $\left(R_{\mathrm{wp}}<4.0 \%\right)$ of all samples, as well as realistic backgrounds, which is a prerequisite for accurate determination of crystallinity. The background level, in particular, highly depends on how the peak shape function is modelled. Testing different sets of refinable parameters, which all resulted in good fits, variations in crystallinity of about 2-3\% were observed, which can be used as an estimate of uncertainty by this method, whereas the relative crystallinity between the different samples remained unaffected.

In general, the crystallinity in rachis is higher than in leaflets, and after pretreatment crystallinities of both leaflets and rachis increase. The crystallinity of pretreated leaflets gradually reduces from $43.2 \%$ at $180^{\circ} \mathrm{C}$ to $38.4 \%$ at $200^{\circ} \mathrm{C}$. Similar downward trend of crystallinity is identified in pretreated rachis, decreasing from $47.3 \%$ to $40.4 \%$ at 180 and $210^{\circ} \mathrm{C}$, respectively. The increase of crystallinity of leaflets and rachis after pretreatment is due to the removal of amorphous cellulose as well as xylan that is also amorphous $[1,42]$. There is an obvious downside trend of crystallinity in pretreated biomass obtained by increasing temperature $\left(180-210^{\circ} \mathrm{C}\right)$, showing the positive effect of pretreatment severity on reducing biomass crystallinity. Moreover, the reduction of crystallinity index during pretreatment could enhance cellulose digestion due to greater enzyme adsorption [43]. Consistent with this, higher cellulose digestibility of pretreated biomass was observed with lower crystallinity index (see Figure 4(a) and Table 2). 


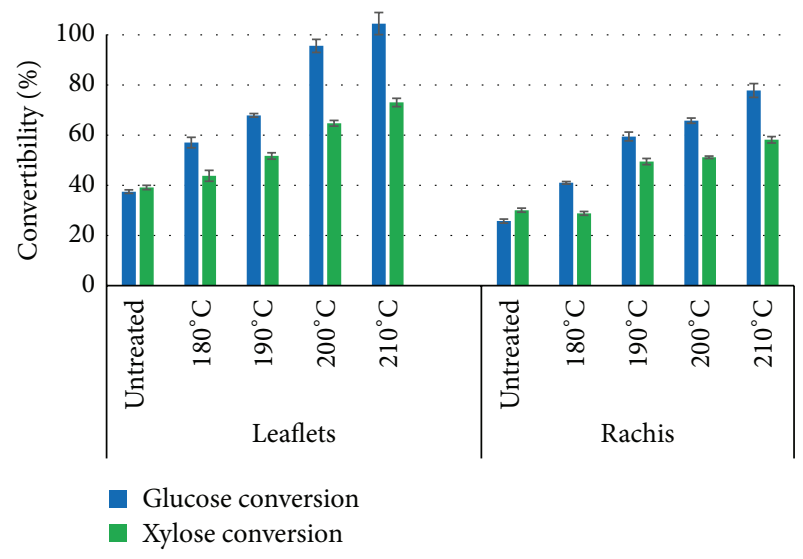

(a)

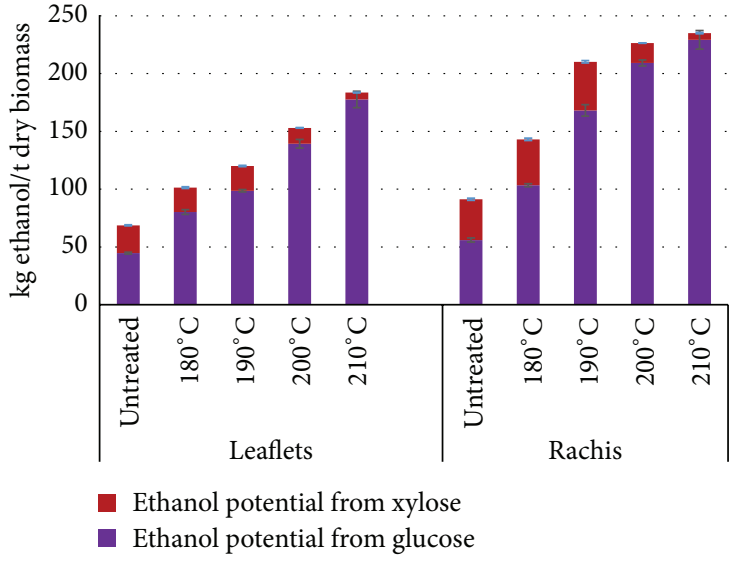

(b)

FIGURE 4: Glucose and xylose conversion and theoretical ethanol yield of untreated and treated date palm leaflets and rachis based on enzymatic hydrolysis. (a) Glucose and xylose conversion of untreated and pretreated leaflets and rachis by enzymatic hydrolysis. (b) Bioethanol potential derived from glucose and xylose of untreated and treated date palm leaflets and rachis based on glucose and xylose yield in enzymatic hydrolysis. Enzymatic hydrolysis was conducted at $50^{\circ} \mathrm{C}$ for $72 \mathrm{~h}$ with Cellic CTec2 $(15 \mathrm{FPU} / \mathrm{g} \mathrm{DM})$ and Cellic HTec2 (1/9 weight of Cellic CTec2).

3.5. Enzymatic Digestibility of Solids from Pretreated Leaflets and Rachis. The enzymatic digestibility of solids from pretreated biomass is one of the most important indexes to evaluate the effectiveness of pretreatment. In this study, the advanced commercial cellulolytic enzymes, Cellic CTec2 and Cellic HTec2, were used in enzymatic hydrolysis of the untreated and hydrothermal pretreated biomass. The hydrothermal pretreatment was capable of enhancing enzymatic digestibilities of both leaflets and rachis (Figure 4(a)). There was a $60 \%$ enhancement of glucan-to-glucose conversion by pretreatment at $210^{\circ} \mathrm{C} / 10 \mathrm{~min}(100 \%$ conversion $)$ compared with untreated leaflets ( $40 \%$ conversion). Although the increase of xylan-to-xylose conversion was less than glucanto-glucose conversion, it was still significant with about $35 \%$ increase. As for rachis, the pretreatment enhancements of glucan-to-glucose (52\% increase) and xylan-to-xylose conversion (28\% increase) were lower than the case for pretreated leaflets. Combined severity factor was also applied as an indicator of biomass digestibility in enzymatic hydrolysis. The coefficient of determination $\left(R^{2}\right)$ between combined severity factor and glucose conversion of pretreated leaflets and rachis was 0.96 and 0.97 , respectively. Theoretical ethanol yield was computed based on the glucose and xylose yield in enzymatic hydrolysis (Figure 4(b)). The highest theoretical ethanol yield was observed at $210^{\circ} \mathrm{C} / 10 \mathrm{~min}$ for both leaflets (183.6 kg/t dry biomass) and rachis (235.0 kg/t dry biomass). As pretreatment temperature of leaflets increased, ethanol from glucose increased from 44.7 (untreated) to $177.7 \mathrm{~kg} / \mathrm{t}$ dry biomass (pretreated at $210^{\circ} \mathrm{C} / 10 \mathrm{~min}$ ), while ethanol from xylose decreased from 24.0 (untreated) to $5.9 \mathrm{~kg} / \mathrm{t}$ dry biomass (pretreated at $210^{\circ} \mathrm{C} / 10 \mathrm{~min}$ ). Similar trend was observed in case of rachis, where glucose-derived ethanol increased from 56.0 (untreated) to $229.3 \mathrm{~kg} / \mathrm{t}$ dry biomass (pretreated at $210^{\circ} \mathrm{C} / 10 \mathrm{~min}$ ), while xylose-derived ethanol decreases from 35.2 (untreated) to $5.8 \mathrm{~kg} / \mathrm{t}$ dry biomass (pretreated at $210^{\circ} \mathrm{C} / 10 \mathrm{~min}$ ).

The results show the great potential of applying hydrothermal pretreatment on processing date palm residues to produce bioethanol due to the boosts of enzymatic digestibility, which was also observed in other lignocellulosic biomass treated by hydrothermal pretreatment [14-17]. In general, the combined severity factor is applied for elaborating the removal of lignin and solubility of xylan that are two influencing factors of enzymatic hydrolysis. From this perspective, combined severity factor can be used to analyze enzymatic digestibility of pretreated biomass. In this study, very strong correlations between combined severity factor and glucan-to-glucose conversion were observed on both pretreated biomass, which could be a good indicator of enzymatic digestibility efficiency. Nevertheless, according to Pedersen's review on relation between $\mathrm{pH}$ and pretreatment severity [25], no evident correlations were observed between enzymatic hydrolysis (glucan-to-glucose conversion) and combined severity factor for acid steam explosion, alkaline wet oxidation, and lime pretreatment. Instead, there was some correlation between the sugar hydrolysis yields (glucose and xylose) and the pretreatment $\mathrm{pH}$, but no correlation with the pretreatment temperature $\left(90-200^{\circ} \mathrm{C}\right)$ based on a quantitative comparison of published data for wheat straw pretreatment [25]. However, it was suggested that temperature showed a greater influence on the pretreatment efficiency than predicted by the severity factor in single hydrothermal pretreatment of mixed hardwoods [44]. The conflicting conclusions were probably due to the different pretreatment methods and type of feedstock applied in previous studies. Combined severity factor was mainly determined by temperature in our study, making it reasonable that there are high correlations between 


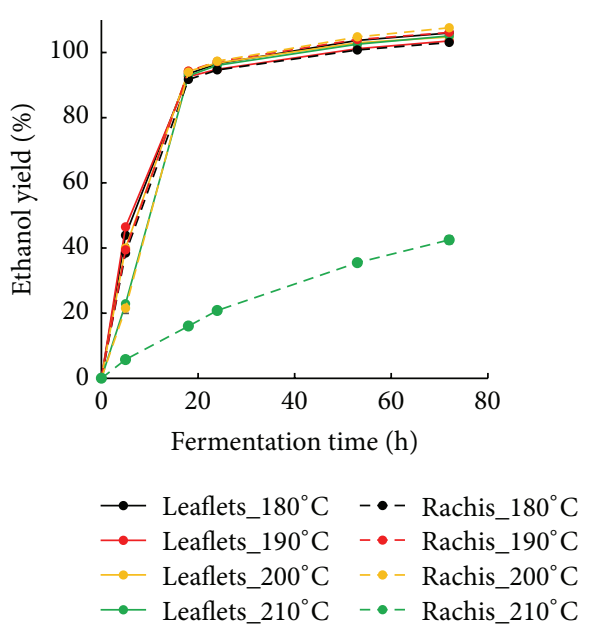

(a)

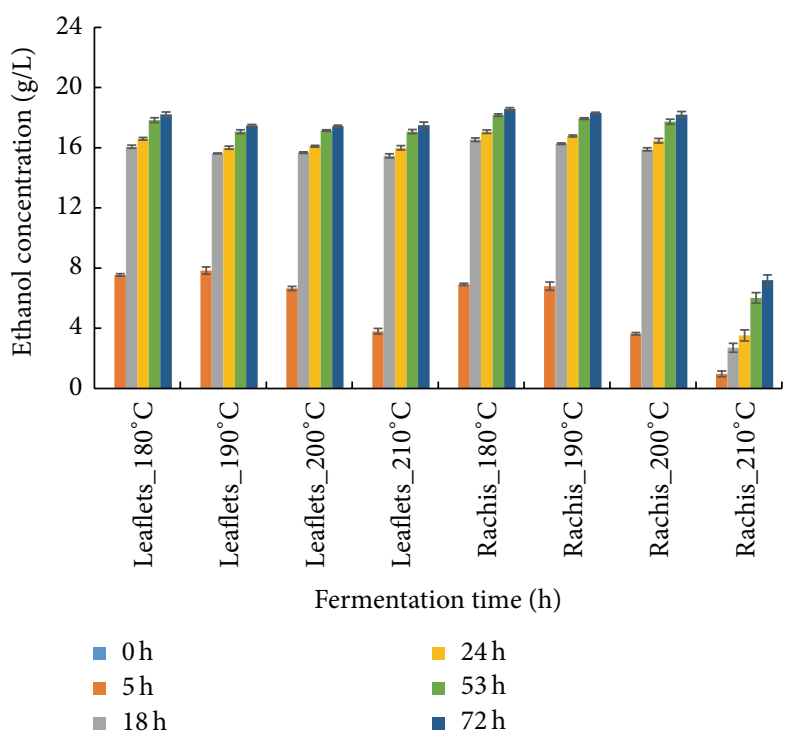

(b)

FIGURE 5: Ethanol yield and corresponding ethanol concentration in the fermentation of liquids from pretreated leaflets and rachis. (a) Ethanol yield in the fermentation of liquids from pretreated leaflets and rachis. (b) Ethanol concentration in the fermentation of liquids from pretreated leaflets and rachis. The fermentation was carried out at $32^{\circ} \mathrm{C}$ for $72 \mathrm{~h}$ with the yeast (S. cerevisiae) inoculation of $2 \mathrm{~g} / \mathrm{L}$.

combined severity factors and hydrolysis. In spite of that, it is necessary to expand the spectrum of conditions to get a validated and accurate index or model to reflect enzymatic digestibility for the sake of optimization of pretreatment. Bioethanol potential of biomass depends on glucose and xylose released in enzymatic hydrolysis (see (6)). Since there are no big changes of glucan recovery in fibers of pretreated biomass (see Figure 1(b)), the increasing contribution to ethanol by glucose is mainly due to the improvement of enzymatic convertibility of glucan-to-glucose. While the decreasing contribution to ethanol by xylose is because of the rapid decrease of xylan recovery along with increase of pretreatment temperature (Figure 1(c)), the optimal condition to maximize bioethanol potential for leaflets and rachis was found $210^{\circ} \mathrm{C} / 10 \mathrm{~min}$, where 183.6 and $235.0 \mathrm{~kg}$ ethanol/t dry biomass was available, respectively.

3.6. Fermentability Test of Pretreatment Liquids. In the pretreatment process, high portion of xylan and small amount of glucan and lignin were removed and solubilized into the liquid stream. As the pretreatment severity increased, a variety of degradation substances (organic acids, phenols, and furans) were generated. These compounds can be inhibitory for ethanol production [45]. In order to evaluate the inhibition to ethanol production, fermentability tests of pretreatment liquids from pretreated leaflets and rachis were conducted. Although strong inhibition was observed in liquids of rachis pretreated at $210^{\circ} \mathrm{C}$, there were no inhibitions when the temperature was below $200^{\circ} \mathrm{C}$ (Figures 5(a) and $5(\mathrm{~b}))$. After $18 \mathrm{~h}$ the ethanol yield and concentration values reached the same level for all the runs except for rachis treated at $210^{\circ} \mathrm{C}$ (Figures 5(a) and 5(b)).
The organic weak acids (formic acid and acetic acid) are the main fermentation inhibitors of ethanol production when comparing organic weak acids, phenols, and furans from steam exploded corn stover [46]. The critical inhibition concentration for acetic acid, furfural, and 5(hydroxymethyl)furfural (HMF) is $6,>4$, and $>4 \mathrm{~g} / \mathrm{L}$, respectively [46]. The high concentration of acetic acid $(18.28 \mathrm{~g} / \mathrm{L})$ rather than furfural $(1.53 \mathrm{~g} / \mathrm{L})$ and $\operatorname{HMF}(2.15 \mathrm{~g} / \mathrm{L})$ in liquids from pretreated rachis at $210^{\circ} \mathrm{C}$ is speculated to be one of the factors responsible for the strong inhibition. The liquid stream after the pretreatment usually contains high amount of pentose especially xylose that cannot be metabolized by Baker's yeast (S. cerevisiae). However, the issue can be overcome by metabolic engineered yeast that is capable of cofermentation of pentose and hexose in both academia and industry [47], indicating high application potential of pretreatment liquids in the future.

\subsection{Simultaneous Saccharification and Fermentation (SSF) of} Pretreated Solids. Simultaneous saccharification and fermentation was applied to investigate the effect of hydrothermal pretreatment on ethanol production (Figure 6). Ethanol yield of leaflets increases from $49 \%(5.89 \mathrm{~g} / \mathrm{L})$ to $96 \%(18.05 \mathrm{~g} / \mathrm{L})$ after pretreatment at $210^{\circ} \mathrm{C} / 10 \mathrm{~min}$. As for the enhancement of ethanol yield by pretreatment of rachis, it rose from $33 \%(7.59 \mathrm{~g} / \mathrm{L})$ to $80 \%(27.90 \mathrm{~g} / \mathrm{L})$. Higher ethanol yield was achieved in leaflets and rachis pretreated at higher temperature.

The results show that higher pretreatment temperature is favorable for higher ethanol conversion for both leaflets and rachis, which is in accordance with the trend in enzymatic hydrolysis. Low or even no inhibition is supposed to be in solids fraction after separation with liquids because 


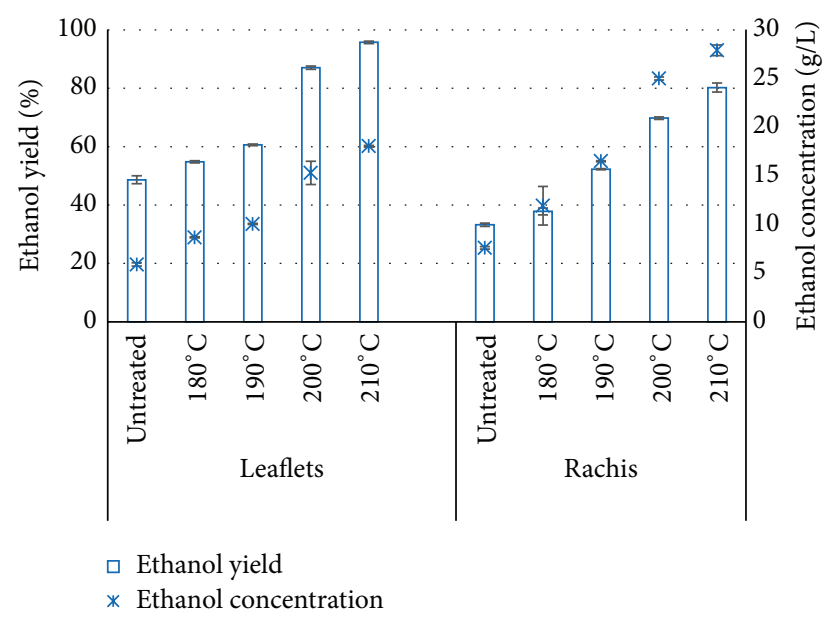

FIGURE 6: Ethanol yield and corresponding ethanol concentration in SSF of solids from untreated and pretreated date palm leaflets and rachis. Enzymatic hydrolysis $(10 \% \mathrm{DM})$ was conducted at $50^{\circ} \mathrm{C}$ for $72 \mathrm{~h}$ with Cellic CTec2 (15 FPU/g DM) and Cellic HTec2 (1/9 weight of Cellic CTec2). In SSF, enzymatic hydrolysis was conducted for $24 \mathrm{~h}$ prior to fermentation that was carried out at $32^{\circ} \mathrm{C}$ for $72 \mathrm{~h}$ with the yeast inoculation (S. cerevisiae) of $2 \mathrm{~g} / \mathrm{L}$.

fermentability test of pretreatment liquids shows almost no inhibition except for rachis treated at $210^{\circ} \mathrm{C} / 10 \mathrm{~min}$. In this case the hydrolysis is speculated to be the limiting step of SSF for production of ethanol. The comparable or even higher ethanol conversion (can be equivalent to glucose conversion) by SSF compared with glucose conversion in enzymatic hydrolysis shows that SSF seems to be a better method for ethanol production from date palm leaflets and rachis than separate hydrolysis and fermentation (SHF). The principal benefits of performing the enzymatic hydrolysis together with fermentation, instead of performing separate step after the hydrolysis, are the reduced end-product inhibition of enzymatic hydrolysis and the reduced investment cost. The principal drawbacks, on the other hand, are the need to find favorable conditions (like temperature and $\mathrm{pH}$ ) for both enzymatic hydrolysis and fermentation $[48,49]$. Optimization of SSF process is affected by several factors, such as cellulase concentration, substrate concentration, temperature, yeast loading, and incubation time [50-53]. The effect of these factors on ethanol production efficiency is planned to be a next step in our research in similar fashion to studies performed by Hari Krishna and Chowdary [50]. For the sake of tech-economic evaluation of the ethanol production from date palm residues, optimization of SSF process is also required in our future work.

\section{Conclusions}

Date palm is playing crucial role in the agriculture in the hot and arid regions. However, utilization of lignocellulosic residues from date palm to produce renewable bioenergy has not been well investigated. In this study, leaflets and rachis were treated by hydrothermal pretreatment. Physicochemical characterization, enzymatic hydrolysis, fermentability test, and SSF of pretreated biomass were applied to evaluate the effectiveness of hydrothermal pretreatment. Noticeable advantages were observed on facilitating structural deconstruction, achieving high sugar recovery, generating no significant fermentation inhibition, and enhancing enzymatic digestibility and ethanol conversion. Optimal pretreatment condition was observed at $210^{\circ} \mathrm{C} / 10 \mathrm{~min}$ by achieving the highest bioethanol potentials.

\section{Conflict of Interests}

The authors declare that there is no conflict of interests regarding the publication of this paper.

\section{Acknowledgments}

This study was supported by MIT\&MI Flagship Project (Biorefinery: Integrated Sustainable Processes for Biomass Conversion to Biomaterials, Biofuels and Fertilizer). Thomas Delclos and Jason Bassett are acknowledged for their technical assistance.

\section{References}

[1] M. E. Himmel, S.-Y. Ding, D. K. Johnson et al., "Biomass recalcitrance: engineering plants and enzymes for biofuels production," Science, vol. 315, no. 5813, pp. 804-807, 2007.

[2] G. Stephanopoulos, "Challenges in engineering microbes for biofuels production," Science, vol. 315, no. 5813, pp. 801-804, 2007.

[3] E. M. Rubin, "Genomics of cellulosic biofuels," Nature, vol. 454, no. 7206 , pp. 841-845, 2008.

[4] B. A. Babcock, S. Marette, and D. Tréguer, "Opportunity for profitable investments in cellulosic biofuels," Energy Policy, vol. 39, no. 2, pp. 714-719, 2011.

[5] P. V. Harris, F. Xu, N. E. Kreel, C. Kang, and S. Fukuyama, "New enzyme insights drive advances in commercial ethanol production," Current Opinion in Chemical Biology, vol. 19, no. 1, pp. 162-170, 2014.

[6] T. R. Brown and R. C. Brown, "A review of cellulosic biofuel commercial-scale projects in the United States," Biofuels, Bioproducts and Biorefining, vol. 7, no. 3, pp. 235-245, 2013.

[7] H. Qiu, L. Sun, J. Huang, and S. Rozelle, "Liquid biofuels in China: current status, government policies, and future opportunities and challenges," Renewable \& Sustainable Energy Reviews, vol. 16, no. 5, pp. 3095-3104, 2012.

[8] R. P. John, G. S. Anisha, K. M. Nampoothiri, and A. Pandey, "Micro and macroalgal biomass: a renewable source for bioethanol," Bioresource Technology, vol. 102, no. 1, pp. 186-193, 2011.

[9] I. Cybulska, T. Chaturvedi, G. P. Brudecki et al., "Chemical characterization and hydrothermal pretreatment of Salicornia bigelovii straw for enhanced enzymatic hydrolysis and bioethanol potential," Bioresource Technology, vol. 153, pp. 165172, 2014.

[10] M. H. Abd-Alla and A.-W. Elsadek El-Enany, "Production of acetone-butanol-ethanol from spoilage date palm (Phoenix dactylifera L.) fruits by mixed culture of Clostridium acetobutylicum and Bacillus subtilis," Biomass and Bioenergy, vol. 42, pp. 172-178, 2012. 
[11] M. Chandrasekaran and A. H. Bahkali, "Valorization of date palm (Phoenix dactylifera) fruit processing by-products and wastes using bioprocess technology-Review," Saudi Journal of Biological Sciences, vol. 20, no. 2, pp. 105-120, 2013.

[12] L. I. El-Juhany, "Degradation of date palm trees and date production in Arab countries: causes and potential rehabilitation," Australian Journal of Basic and Applied Sciences, vol. 4, no. 8, pp. 3998-4010, 2010.

[13] M. Mallaki and R. Fatehi, "Design of a biomass power plant for burning date palm waste to cogenerate electricity and distilled water," Renewable Energy, vol. 63, pp. 286-291, 2014.

[14] B. C. Saha, T. Yoshida, M. A. Cotta, and K. Sonomoto, "Hydrothermal pretreatment and enzymatic saccharification of corn stover for efficient ethanol production," Industrial Crops and Products, vol. 44, pp. 367-372, 2013.

[15] M. Ø. Petersen, J. Larsen, and M. H. Thomsen, “Optimization of hydrothermal pretreatment of wheat straw for production of bioethanol at low water consumption without addition of chemicals," Biomass and Bioenergy, vol. 33, no. 5, pp. 834-840, 2009.

[16] S. Kumar, U. Kothari, L. Kong, Y. Y. Lee, and R. B. Gupta, "Hydrothermal pretreatment of switchgrass and corn stover for production of ethanol and carbon microspheres," Biomass and Bioenergy, vol. 35, no. 2, pp. 956-968, 2011.

[17] A. Romaní, G. Garrote, J. L. Alonso, and J. C. Parajó, "Bioethanol production from hydrothermally pretreated Eucalyptus globulus wood," Bioresource Technology, vol. 101, no. 22, pp. 8706-8712, 2010.

[18] N. Gilbert, "Local benefits: the seeds of an economy," Nature, vol. 474, no. 7352, pp. S18-S19, 2011.

[19] S. T. Thomsen, Z. Kádár, and J. E. Schmidt, "Compositional analysis and projected biofuel potentials from common West African agricultural residues," Biomass and Bioenergy, vol. 63, pp. 210-217, 2014.

[20] A. J. A. van Maris, D. A. Abbott, E. Bellissimi et al., "Alcoholic fermentation of carbon sources in biomass hydrolysates by Saccharomyces cerevisiae: current status," Antonie van Leeuwenhoek, vol. 90, no. 4, pp. 391-418, 2006.

[21] H. Rouhollah, N. Iraj, E. Giti, and A. Sorah, "Mixed sugar fermentation by Pichia stipitis, Sacharomyces cerevisiaea, and an isolated xylosefermenting Kluyveromyces marxianus and their cocultures," African Journal of Biotechnology, vol. 6, no. 9, pp. 1110-1114, 2007.

[22] L. Pinilla, R. Torres, and C. Ortiz, "Bioethanol production in batch mode by a native strain of Zymomonas mobilis," World Journal of Microbiology and Biotechnology, vol. 27, no. 11, pp. 2521-2528, 2011.

[23] A. Sluiter, R. Ruiz, C. Scarlata, J. Sluiter, and D. Templeton, Determination of Extractives in Biomass, NREL/TP-510-42619, National Renewable Energy Laboratory, 2008.

[24] A. Sluiter, B. Hames, R. Ruiz et al., Determination of Structural Carbohydrates and Lignin in Biomass, NREL/TP-510-42618, National Renewable Laboratory, 2008.

[25] M. Pedersen and A. S. Meyer, "Lignocellulose pretreatment severity-relating $\mathrm{pH}$ to biomatrix opening," New Biotechnology, vol. 27, no. 6, pp. 739-750, 2010.

[26] M. M. Bradford, "A rapid and sensitive method for the quantitation of microgram quantities of protein utilizing the principle of protein-dye binding," Analytical Biochemistry, vol. 72, no. 1-2, pp. 248-254, 1976.
[27] M. Selig, N. Weiss, and Y. Ji, "Enzymatic saccharification of lignocellulosic biomass: laboratory analytical procedure," National Renewable Energy Laboratory NREL/TP-510-42629, 2008.

[28] T. A. Bewick, D. G. Shilling, and R. Querns, "Evaluation of epicuticular wax removal from whole leaves with chloroform," Weed Technology, vol. 7, no. 3, pp. 706-716, 1993.

[29] A. Thygesen, J. Oddershede, H. Lilholt, A. B. Thomsen, and K. Ståhl, "On the determination of crystallinity and cellulose content in plant fibres," Cellulose, vol. 12, no. 6, pp. 563-576, 2005.

[30] L. P. de Figueiredo and F. F. Ferreira, "The Rietveld method as a tool to quantify the amorphous amount of microcrystalline cellulose," Journal of Pharmaceutical Sciences, vol. 103, no. 5, pp. 1394-1399, 2014.

[31] T. S. Khan and U. Mubeen, "Wheat straw: a pragmatic overview," Current Research Journal of Biological Sciences, vol. 4, no. 6, pp. 673-675, 2012.

[32] A. J. Ragauskas, G. T. Beckham, M. J. Biddy et al., "Lignin valorization: improving lignin processing in the biorefinery," Science, vol. 344, no. 6185, Article ID 1246843, 2014.

[33] T. A. Lloyd and C. E. Wyman, "Combined sugar yields for dilute sulfuric acid pretreatment of corn stover followed by enzymatic hydrolysis of the remaining solids," Bioresource Technology, vol. 96, no. 18, pp. 1967-1977, 2005.

[34] B. S. Donohoe, S. R. Decker, M. P. Tucker, M. E. Himmel, and T. B. Vinzant, "Visualizing lignin coalescence and migration through maize cell walls following thermochemical pretreatment," Biotechnology and Bioengineering, vol. 101, no. 5, pp. 913925, 2008.

[35] M. J. Selig, S. Viamajala, S. R. Decker, M. P. Tucker, M. E. Himmel, and T. B. Vinzant, "Deposition of lignin droplets produced during dilute acid pretreatment of maize stems retards enzymatic hydrolysis of cellulose," Biotechnology Progress, vol. 23, no. 6, pp. 1333-1339, 2007.

[36] H. Li, Y. Pu, R. Kumar, A. J. Ragauskas, and C. E. Wyman, "Investigation of lignin deposition on cellulose during hydrothermal pretreatment, its effect on cellulose hydrolysis, and underlying mechanisms," Biotechnology and Bioengineering, vol. 111, no. 3, pp. 485-492, 2014.

[37] Y. Pu, F. Hu, F. Huang, B. H. Davison, and A. J. Ragauskas, "Assessing the molecular structure basis for biomass recalcitrance during dilute acid and hydrothermal pretreatments," Biotechnology for Biofuels, vol. 6, no. 1, pp. 15-27, 2013.

[38] R. Kumar, F. Hu, P. Sannigrahi, S. Jung, A. J. Ragauskas, and C. E. Wyman, "Carbohydrate derived-pseudo-lignin can retard cellulose biological conversion," Biotechnology and Bioengineering, vol. 110, no. 3, pp. 737-753, 2013.

[39] S.-Y. Ding, Y.-S. Liu, Y. Zeng, M. E. Himmel, J. O. Baker, and E. A. Bayer, "How does plant cell wall nanoscale architecture correlate with enzymatic digestibility?" Science, vol. 338, no. 6110, pp. 1055-1060, 2012.

[40] A. Bendahou, Y. Habibi, H. Kaddami, and A. Dufresne, "Physico-chemical characterization of palm from Phoenix Dactylifera L., preparation of cellulose whiskers and natural rubber-based nanocomposites," Journal of Biobased Materials and Bioenergy, vol. 3, no. 1, pp. 81-90, 2009.

[41] A. K. Chandel, F. A. F. Antunes, V. Anjos et al., "Multiscale structural and chemical analysis of sugarcane bagasse in the process of sequential acid-base pretreatment and ethanol production by Scheffersomyces shehatae and Saccharomyces cerevisiae," Biotechnology for Biofuels, vol. 7, article 63, 2014. 
[42] R. Kumar, G. Mago, V. Balan, and C. E. Wyman, "Physical and chemical characterizations of corn stover and poplar solids resulting from leading pretreatment technologies," Bioresource Technology, vol. 100, no. 17, pp. 3948-3962, 2009.

[43] R. Kumar and C. E. Wyman, "Effect of enzyme supplementation at moderate cellulase loadings on initial glucose and xylose release from corn stover solids pretreated by leading technologies," Biotechnology and Bioengineering, vol. 102, no. 2, pp. 457467, 2009.

[44] Y. Kim, T. Kreke, N. S. Mosier, and M. R. Ladisch, "Severity factor coefficients for subcritical liquid hot water pretreatment of hardwood chips," Biotechnology and Bioengineering, vol. 111, no. 2, pp. 254-263, 2014.

[45] J. R. M. Almeida, T. Modig, A. Petersson, B. Hähn-Hägerdal, G. Lidén, and M.-F. Gorwa-Grauslund, "Increased tolerance and conversion of inhibitors in lignocellulosic hydrolysates by Saccharomyces cerevisiae," Journal of Chemical Technology and Biotechnology, vol. 82, no. 4, pp. 340-349, 2007.

[46] H. Huang, X. Guo, D. Li, M. Liu, J. Wu, and H. Ren, "Identification of crucial yeast inhibitors in bio-ethanol and improvement of fermentation at high $\mathrm{pH}$ and high total solids," Bioresource Technology, vol. 102, no. 16, pp. 7486-7493, 2011.

[47] D. Runquist, B. Hahn-Hägerdal, and M. Bettiga, "Increased expression of the oxidative pentose phosphate pathway and gluconeogenesis in anaerobically growing xylose-utilizing Saccharomyces cerevisiae," Microbial Cell Factories, vol. 8, pp. 4960, 2009.

[48] F. Alfani, A. Gallifuoco, A. Saporosi, A. Spera, and M. Cantarella, "Comparison of SHF and SSF processes for the bioconversion of steam-exploded wheat straw," Journal of Industrial Microbiology \& Biotechnology, vol. 25, no. 4, pp. 184-192, 2000.

[49] K. Olofsson, M. Bertilsson, and G. Lidén, "A short review on $\mathrm{SSF}$ - an interesting process option for ethanol production from lignocellulosic feedstocks," Biotechnology for Biofuels, vol. 1, article 7, 2008.

[50] S. Hari Krishna and G. V. Chowdary, "Optimization of simultaneous saccharification and fermentation for the production of ethanol from lignocellulosic biomass," Journal of Agricultural and Food Chemistry, vol. 48, no. 5, pp. 1971-1976, 2000.

[51] P. Sassner, M. Galbe, and G. Zacchi, "Bioethanol production based on simultaneous saccharification and fermentation of steam-pretreated Salix at high dry-matter content," Enzyme and Microbial Technology, vol. 39, no. 4, pp. 756-762, 2006.

[52] M. Linde, M. Galbe, and G. Zacchi, "Simultaneous saccharification and fermentation of steam-pretreated barley straw at low enzyme loadings and low yeast concentration," Enzyme and Microbial Technology, vol. 40, no. 5, pp. 1100-1107, 2007.

[53] K. Olofsson, A. Rudolf, and G. Lidén, "Designing simultaneous saccharification and fermentation for improved xylose conversion by a recombinant strain of Saccharomyces cerevisiae," Journal of Biotechnology, vol. 134, no. 1-2, pp. 112-120, 2008.

[54] C. Li, G. Cheng, V. Balan et al., "Influence of physico-chemical changes on enzymatic digestibility of ionic liquid and AFEX pretreated corn stover," Bioresource Technology, vol. 102, no. 13, pp. 6928-6936, 2011.

[55] F. Xu, J. Yu, T. Tesso, F. Dowell, and D. Wang, "Qualitative and quantitative analysis of lignocellulosic biomass using infrared techniques: a mini-review," Applied Energy, vol. 104, pp. 801809, 2013.

[56] R. J. Sammons, D. P. Harper, N. Labbé, J. J. Bozell, T. Elder, and T. G. Rials, "Characterization of organosolv lignins using thermal and FT-IR spectroscopic analysis," BioResources, vol. 8, no. 2, pp. 2752-2767, 2013. 

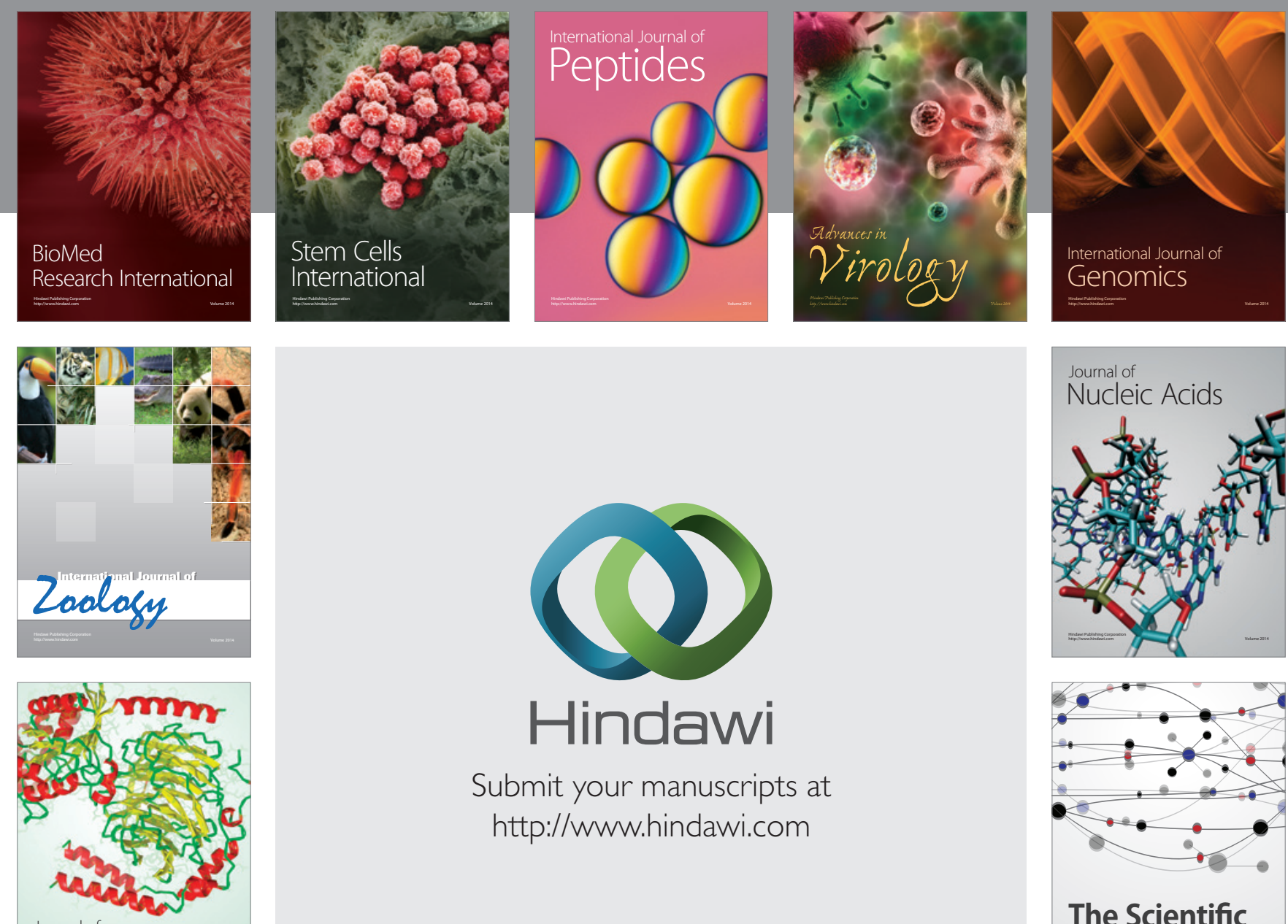

Submit your manuscripts at

http://www.hindawi.com

Journal of
Signal Transduction
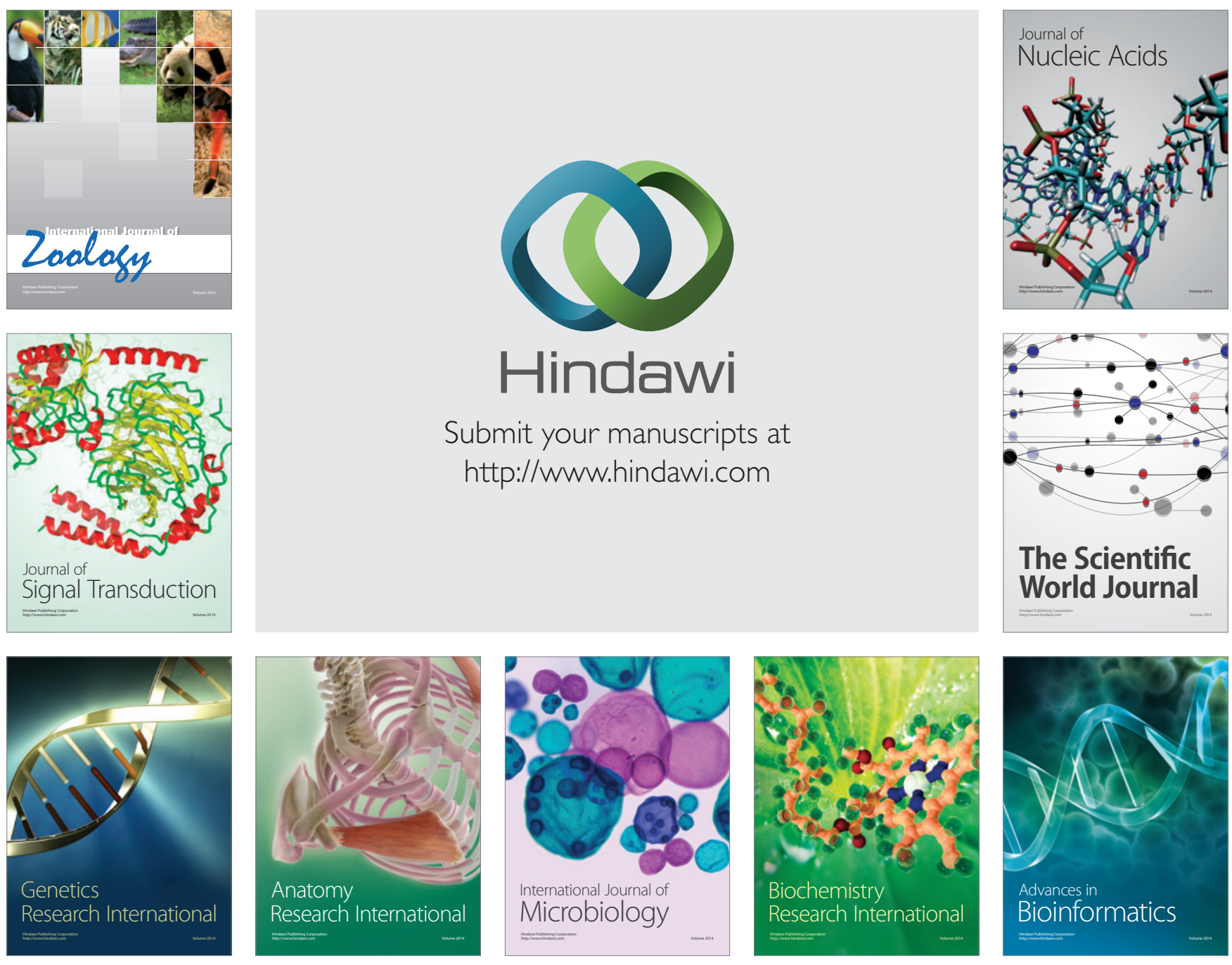

The Scientific World Journal
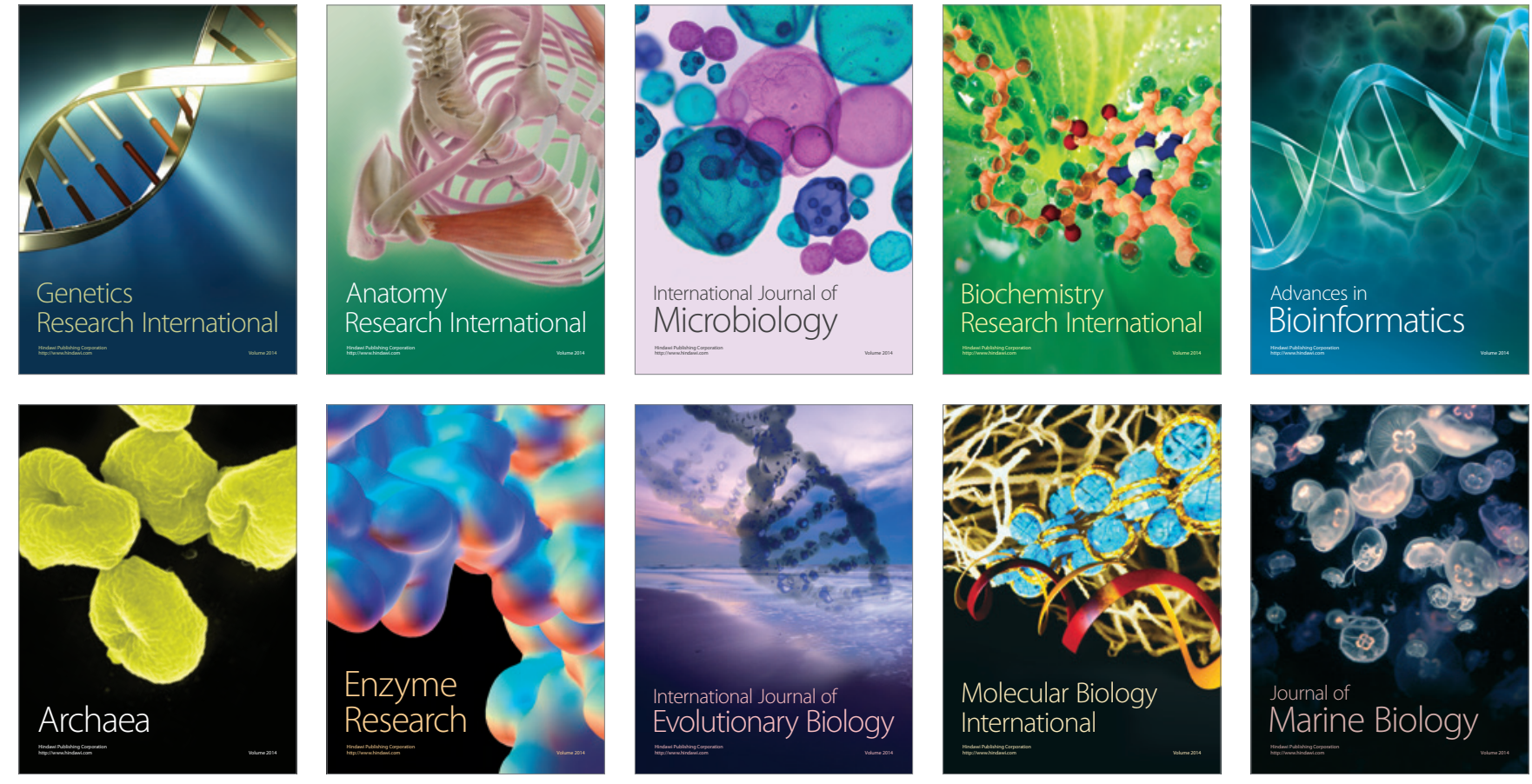